\title{
An Epidemiological Study of Acute Poisoning In a Tertiary Care Centre
}

\author{
Jain Pankaj Kumar ${ }^{1}$, katara Kamalesh², Jelia S.C ${ }^{3}$
}

1. Associate Professor, Department of Medicine, Government Medical College, Kota, Rajasthan, India

2. Post Graduate Student, Department of Medicine, Government Medical College, Kota, Rajasthan, India

3. Senior Professor, Department of Medicine, Government Medical College, Kota, Rajasthan, India

Corresponding Author: Dr. Pankaj Kumar Jain,Department of Medicine, Government Medical College, Kota,Rajasthan, India. Mobile No. : 9828515173 E-mail ： docs.pankajjain@gmail.com

Received: 1/12/2020

Peer review: 12/1/2021

Accepted: 21/1/2021

DOI:10.47799/pimr.0902.08

\section{ABSTRACT}

Introduction: Acute poisoning represents a real health threat in the world. It is a common cause of admission to emergency department and in intensive care unit. Periodic clinical and epidemiological studies are required to understand the pattern of poisoning. This study aims to analyze epidemiological aspect, clinical profile, and outcome of acute poisoning in a tertiary care hospital.

Material and Methods: A cross sectional study was conducted at Government Medical College Hospital, Kota, Rajasthan. 102 admitted patients were taken for study from January 2020 to August 2020. Epidemiological variables age, sex, type of poison, mode of exposure, clinical presentation and outcome were studied.

Results: The median age was 30.23 years with a male predominance (54.9\%). The circumstances of poisoning were suicidal, accidental and unknown in $88.2 \%, 9.8 \%$, and $1.96 \%$ respectively. Ingestion was the major route of exposure (98\%) followed by inhalation (1.96\%). The majority 33(32.4\%) of cases were of Organophosphorus poisoning followed by $17(16.7 \%)$ cases of Rodenticide poisoning. The main symptoms were nausea and vomiting in 90(88.2\%) cases. Convulsions were noted in $3(2.9 \%)$ patients. Gastric lavage was done for 92(90.19\%). 8 patients $(7.84 \%)$ were needed mechanical ventilation. 7 patients $(6.86 \%)$ were needed vasoactive drugs. The rate of mortality was $8.82 \%$. The aluminium phosphide poisoning was responsible for $44.4 \%$ deaths.

Conclusion: Study revealed the high mortality associated with acute poisoning. Appropriate approach towards poisoning at tertiary care center and prevention remains the best strategy for reducing morbidity and mortality.
Key words: Acute poisoning, intensive care unit, mortality, organophosphorus compound.

\section{INTRODUCTION}

Acute poisoning is exposure to a poison on one occasion or during a short period of time. The exposure may be ora ingestion, dermal or ophthalmic contact, inhalation and parental injection ${ }^{1}$. The incidence of accidental and suicidal poisoning is increasing day by day. It is considered a real global health problem and is a frequent reason for admission in the hospital ${ }^{2}$. In developing countries, the mortality related to acute poisoning is very high. This high mortality reflects the wide availability of highly toxic components such as pesticides and limited resources to treat poison patients. The exact incidence of poisoning in India remains uncertain but 1 to 1.5 million cases occurs every year of which 50,000 succumb to it. It has been estimated that, in India five to six person per lakh population die due to acute poisoning every year ${ }^{3}$. The pattern of poisoning varies from region to region depending on factors like geography, accessibility, and availability of poison, socioeconomical conditions and cultural and religious influences. In India, majority of population is employed in agriculture so poisoning due to pesticides is more common. Next to pesticides, drug overdose were shown to be more common agent of poisoning in India 4 . Poisoning is the leading cause of unnatural morbidity and mortality in India. Periodic Epidemiological and clinical studies are necessary to understand the pattern of poisoning in each region.

The present study was undertaken to study epidemiological characteristics, common clinical manifestations, reasoning, outcome and complications of different poisoning among cases of poisoning admitted at a tertiary care center. 


\section{MATERIAL AND METHODS}

In this cross sectional study, 102 patients ; older than 14 years of age with acute poisoning, treated in the medical ward and intensive care unit at Government Medical College Hospital, Kota, Rajasthan during January 2020 to August 2020 were included. We collected following specifications for every patient : age, sex, past history of psychological disorder, past suicidal attempts, type and number of toxic agents, route of exposure, reason of poisoning, signs and symptoms of intoxication, delay in presentation to hospital, therapeutic intervention, vital signs, oxygen saturation, outcome and rate of mortality. Patient with idiosyncratic or adverse reaction to prescribed drug, food poisoning, snake bite, arthropod bite were excluded from the study. The nature of poison involved was determined from the circumstantial evidence, reliable history, presentation of remaining stuff/container from which the poison had been consumed / exposed and suggestive clinical features. A complete history, general examination and systematic examination were carried out in each case. In examination, particular emphasis was given on vital signs, smell from mouth/ vomiting/ clothes, type of breathing, pupillary size and reaction to light. All patients were investigated by routine blood investigations like complete blood count, blood sugar, blood urea, serum creatinine, serum electrolytes, liver function tests, urine examination, chest X-ray and ECG.

Treatment was given specific to the cases and outcome was observed. Ethical approval was taken from the Institutional Ethical Committee. Data was analyzed using Microsoft Excel and descriptive statistics obtained were the numbers and percentages.

\section{RESULTS}

102 cases of acute poisoning admitted in our hospital from January 2020 to August 2020 were taken for study.Majority of poisoning cases were between 20-29 years of age (32.4\%). $17.6 \%$ of the patients were under 20 years. The majority of patients were young with a median age of 30.23 years (range 15-65). Male cases (54.9\%) were more than female (45\%) with male to female ratio being 1.22:1.4. Majority of the cases $(57.8 \%)$ were from rural area and $(42.1 \%)$ cases were from urban area. 13 patients had a history of past psychiatric illness $(12.7 \%)$.Suicide was the most common mode of poisoning (88.2\%). The circumstances of poisoning were accidental in 10 cases $(9.8 \%)$ and unknown in 2 cases $(1.96 \%)$. Ingestion was the major route of exposure (98\%), followed by inhalation (1.96\%). 2 patients $(1.96 \%)$ had a history of suicidal attempts.

In the present study, organophosphorus compounds (32.4\%) were the most commonly used poison followed by Rodenticide (16.7\%) Poison (Table1). The main symptoms were nausea and vomiting in 90 cases (88.2\%). Convulsions were noted in 3 patients (2.9\%). Tachycardia in 25 cases $(24.5 \%)$ and hypotension in 12 cases (11.8\%). 15 patients (14.7\%) had respiratory distress at admission.

Table 1: Incidence and types of acute poisoning

\begin{tabular}{|c|c|c|c|}
\hline S.No. & Name of poison & Number of cases & Percentage (\%) \\
\hline 1. & Organophosphorus compounds & 33 & $32.4 \%$ \\
\hline 2. & Aluminium Phosphide & 11 & $10.8 \%$ \\
\hline 3. & Corrosive & 8 & $7.8 \%$ \\
\hline 4. & Rodenticide & 17 & $16.7 \%$ \\
\hline 5. & Unknown & 14 & $13.7 \%$ \\
\hline 6. & Drugs & 10 & $9.8 \%$ \\
\hline 7. & Herbicide & 05 & $4.9 \%$ \\
\hline 8. & Alcohol & 04 & $3.9 \%$ \\
\hline
\end{tabular}

On arrival of the patients to emergency ward, the following parameters were monitored (heart rate, respiratory rate, blood pressure, Spo2). Gastric lavage was done for 92 patients $(90.19 \%) .8$ patients $(7.84 \%)$ were needed mechanical ventilation and 7 patients $(6.86 \%)$ have been placed under vasoactive drugs in Intensive Care Unit (ICU). 9 patients died. The rate of mortality was $8.82 \%$. Maximum mortality was related to Aluminium phosphide poisoning (44.4\%) followed by organophosphorus compounds (33.3\%). All survivors have received psychiatric counseling and treatment.

\section{DISCUSSION}

The incidence of hospitalization for poisoning cases is steadily increasing. Acute poisoning is a major public health 
problem worldwide. The majority of our patients were young with a median age of 30.23 years, which is often repeated by the other authors. The average age in studies of Senarathna5 and Mortazavi6 was respectively 24 and 26.82 years. In the present study, the majority of the patients were from age group
20-29 (32.4\%) followed by 30-39 age group. The incidence in other studies like S.K. Dash et $\mathrm{al}^{7}$ and Joshi M. et al8 were similar (Table 2).

Table 2: Comparison of age groups of patients with other studies

\begin{tabular}{|c|c|c|c|}
\hline Age (Years) & S.K. Dash et al (\%) & Joshi M et al (\%) & Present study (\%) \\
\hline Less than 20 & 23.2 & 10 & 17.6 \\
\hline $20-29$ & 40.5 & 56.6 & 32.4 \\
\hline $30-39$ & 21.6 & 20.8 & 28.4 \\
\hline 40 and above & 14.7 & 12.6 & 21.6 \\
\hline
\end{tabular}

High incidence in this age is obvious due to the fact that this age group is exposed to several determining factors of life in terms of studies, services, marriage and other life settlements, so they are subjected to mental stress. Males, 56 (54.9\%) were more commonly affected than females, 46 (45\%) in our study. Both in S.K. Das et al ${ }_{7}$ and Bhoopendra Singh et al9 found same results. Ratio between males and females in our study was 1.22:1. In a study conducted by Multani et $\mathrm{al}^{10}$, the male and female ratio was 1.5:1.

The higher incidence in males may be because males are more exposed to stress and occupational hazards compared to females. In the present study, out of 102 cases 59 (57.8\%) cases were from rural area and $43(42.2 \%)$ cases were from urban areas. In a study conducted by Bansal et al, $58.1 \%$ cases were from rural areas ${ }^{11}$. The poisoning was mostly suicidal (88.2\%), followed by accidental (9.8\%). Table-3 shows the comparison of nature of poisoning with other studies. Increase in suicidal cases may be due to unemployment, urbanization, breakup in family support system, economic instability etc. Route of poisoning in all suicidal cases was ingestion.

Table 3: Comparison of nature of poisoning with other studies

\begin{tabular}{|c|c|c|c|c|}
\hline Nature of Poison & $\begin{array}{c}\text { M. Shoaib Zaheer } \\
\text { et al }^{12}(\%)\end{array}$ & $\begin{array}{c}\text { Bhupinder Singh } \\
\text { et al }^{9}(\%)\end{array}$ & $\begin{array}{c}\text { Joshi } \\
\text { et al }^{8}(\%)\end{array}$ & Present study (\%) \\
\hline Suicidal & 80.8 & 69 & 80 & 88.2 \\
\hline Accidental & 15.4 & 28 & 15.8 & 9.8 \\
\hline Homicidal & 3.8 & 3 & 4.2 & 2.0 \\
\hline
\end{tabular}

In the present study maximum cases were due to organophosphorus compounds (32.4\%) followed by rodenticides (16.7\%). Other types were Aluminium phosphide $(10.8 \%)$, drug poisons $(9.8 \%)$, corrosives $(7.8 \%)$, herbicides (4.9\%), alcohol (3.9\%) and unknown poison cases were $13.7 \%$. Similar to our study organophosphorus compound was the most common agent in a study conducted by Vaidya et $\mathrm{al}^{13}$, Devi at el ${ }^{14}$, Joshi et al 8 by a percentage of $35.46 \%, 43.4 \%$ and $25.8 \%$ respectively. In our study 9 patients died. The rate of mortality was $8.82 \%$, which is similar to Boukatta et al ${ }^{15}(10.9 \%)$.

In our study maximum mortality was related to Aluminium phosphide 4 (44.4\%) followed by organophosphorus compound $3(33.3 \%)$ which is coincide with the study conducted by Boukatta et al 18 (81.8\%).

Though a number of factors such as dose consumed, level of available medical facilities, time interval between intake of poison and arrival at hospital, can affect outcome $e^{16,17}$. The prevention remains the best approach for reducing morbidity and mortality. Main preventive measures consist of restricting the sale so that pesticides will not be available to general public.

\section{Conclusion}

Acute poisoning represents a big health threat in the world. It's a very common cause of admission to emergency departments and in the intensive care unit. Organophosphorus compounds are the most common cause, especially in developing countries like India. The management of poisoning consists of symptomatic treatment, decontamination, specific antidotal therapy and general supportive measures. The mortality rate is high and the prevention remains the best approach for reducing morbidity and mortality.

\section{REFERENCES}

1. Jesslin J, Adepu R, Churi S (2010) Assessment of prevalence and mortality incidences due to poisoning in a south 
Indian tertiary care teaching hospital. Indian J Pharm Sci 72: 587-591.

2. Megarbane B, Alazia M, Baud F (2006) Severe poisoning in adults: epidemiology, definition, and criteria of admission in intensive care units. Reanimation 15: 354363.

3. Narindar Pal Singh, Gurleen Kaur. Poisoning: Basic consideration and epidemiology. API Textbook of Medicine 2015; 26: 2628-2631.

4. K.S. Narayan Reddy. The essential of Forensic Medicine and Toxicology, 21st edition, page 403-420.

5. Senarathna L, Jayamanna SF, Kelly PJ, Buckley NA, Dibley MJ, et al. (2012) Changing epidemiological patterns of deliberate self poisoning in a rural district of Sri Lanka. BMC public health 12: 593-600.

6. Mortazavi SM, Haaji Y, Khonche A, Jamilian H (2012) Epidemiology and causes of poisoning in patients referred to Loqman Hospital, Teheran, Iran during summer 2010. Iranian J of Toxicology 17: 642-648.

7. Dash S.K., Mohanty MK, Patnaik KK (2005). Socio Demographic profile of poisoning cases.JIAFM ;27(3):133138

8. Joshi M, Divyeshkumar V. Patel (2015). A study on clinical profile of patients with acute poisoning. GCSMC J Med Sci 2015 Jul- Dec, Vol (IV) 97- 100.

9. Unnikrishnan D, Singh B, Rajiv A (2005). Trends of Acute Poisoning in South Karnataka. Kathmandu University Medical Journal: Vol 3, No.2, issue 10,149-154.

10. Multani AS, Bal BS, Singh SP, Singh TP, Salwan S, Shivcharan. Spectrum of acute poisoning in medical emergencies- a prospective study. JAPI 2003; 51: 11991200.

11. Bansal N, Uniyal N, Kashyap PV, Verma A. A profile of poisoning in Uttarakhand. Transworld Medical Journal. 1 (4): 128-130.

12. M. Shoaib Zaheer, M Aslam, Vibhanshu Gupta, Vibhor Sharma and Shadab Ahmed Khan. (2009) Profile of Poisoning cases at a North Indian Tertiary Care Hospital. HPPI 32.

13. Vaidya YP, Hulke SM. Study of trends of poisoning in the cases reported to Government Hospital, Yavatmal. Chron Young Sci 2012; 3: 63-70.

14. Devi S, Dasari A, Dasyam SK, Sai Shripada Rao K. A study of clinical profile of 30 consecutive cases of poisoning presenting to a rural tertiary care center. Perspectives in Medical Research 2014; 2: 28-32.

15. Boukatta B, El Bouazzaoui A, Guemoune R, Houari N,
Achour S.et al.(2014) An Epidemiological Study of Adult Acute Poisoning in Fez:Morocco.J Clin Toxicol 4:219.

16. Sena Nayake N., Petris H. Mortality due to poisoning in a developing and agricultural country, trends over 20 years.1995 oct ; 14(10): 808-811.

17. Ramesha KN, Rao KBM Kumar GS (2009) Pattern and outcome of acute poisoning cases in a tertiary care hospital in Karnataka, India. Indian J Crit Care Med (13):152-155.

How to cite this article : Jain Pankaj Kumar, katara Kamalesh, Jelia S.C. An Epidemiological Study of Acute Poisoning In a Tertiary Care Centre. Perspectives in Medical Research 2021; 9 (2):34-37 DOI:10.47799/pimr.0902.08

Sources of Support: Nil, Conflict of interest: None declared 